\title{
Cyberspace as an Example of Self-Organisation from a Network Perspective
}

\author{
Cäcilia Maria Hermes* \\ Berlin, Germany \\ cc.hermes@googlemail.com
}

Abstract

Keywords $\quad 818$

$\begin{array}{lr}\text { I. Introduction } & 818\end{array}$

$\begin{array}{ll}\text { II. Regulation of Cyberspace } & 820\end{array}$

1. IETF

a) IETF's Structure and Working Procedure $\quad 820$

b) IETF's Networked Standard Setting $\quad 821$

2. ICANN $\quad 822$

a) ICANN's Evolution $\quad 822$

b) ICANN's Structure and Working Procedure 823

(i) Stakeholder Structure $\quad 823$

(ii) Individual Internet Users $\quad 824$

(iii) Governments $\quad 825$

c) Touchstone: The $x x x$-Case $\quad 825$

d) Hybrid Regulation of a Global Resource $\quad 826$

$\begin{array}{lr}\text { 3. IGF } & 827\end{array}$

a) Evolution of the IGF $\quad 827$

b) Structure and Processes, Criticism and Reform 827

c) Towards Comprehensive Cyberspace Regulation? 829

4. Interim Conclusion $\quad 829$

III. Networks as Regularity in Irregularity $\quad 830$

1. Network Perspective $\quad 830$

a) Early Reception of Networks in International Relations 831

b) Reception of Networks in International Law Scholarship 832

2. Cyberspace Governance Through the Lens of Network Perspective 834

a) IETF, ICANN and IGF as Non-State Networks 834

b) The Legitimacy of Networks and Their Decisions 834

c) Feeding and Exploiting of the Knowledge Pool 835

d) Networks' Law and Legal Quality $\quad 837$

3. Order and Legitimacy Through Networks 838

$\begin{array}{ll}\text { IV. Concluding Remarks } & 838\end{array}$

\begin{abstract}
The present contribution defends network theory empirically by considering the governance of cyberspace. It aims to normatively explain the largely

* Ph.D. student at the Institute of International Law at the University of Giessen, researching on the emergence of norms in cyberspace.
\end{abstract}


non-state regulation of cyberspace with the help of network theory. To this end, it first introduces key conglomerates of cyberspace governance and analyses their structures and processes. The empirical analysis of the organisational structures forms the basis for the concluding theoretical evaluation. The contribution can serve as an impulse for further research on global governance in a departure from state-centred perceptions.

\section{Keywords}

network theory - cyberspace governance - norm development

\section{Introduction}

It is particularly in the context of cyberspace governance that decisions affecting citizens' daily lives worldwide and directly - are made without being preceded by political will-building processes. The question therefore arises whether and how these decisions are legitimised.

Cyberspace is a global electronic communication system that allows both computers and their users to network in order to exchange information. Thus, cyberspace embraces two dimensions: on the one hand, it contains a technical infrastructure that enables electronic communication between computerised devices, ${ }^{1}$ but on the other hand, it also contains the social aspect of its use by different actors. ${ }^{2}$ A number of diverse participants are involved in the regulation of Cyberspace: Companies that provide tools for its infrastructure, user devices and applications, institutions that guarantee the interoperability of networks and devices by either developing Internet protocols and standards ${ }^{3}$ or by managing the Internet's address system, ${ }^{4}$ and governments that have an interest in ensuring that their normative decisions are not undermined in Cyberspace, to name only a few. All these actors pursuing their own interests make their respective decisions of either technical or political nature. Yet, their ways of decision-

1 David J. Betz and Tim Stevens, Cyberspace and the State: Towards a Strategy for CyberPower (London: Routledge 2011), 13; Elisabeth Longworth, 'The Possibilities for a Legal Framework for Cyberspace - Including a New Zealand Perspective' in: Bruno de Padirac (ed.), The International Dimensions of Cyberspace Law (London: Routledge 2019), 4.

2 David Gioe, Michael S. Goodman and Alicia Wanless, 'Rebalancing Cybersecurity Imperatives: Patching the Social Layer', Journal of Cyber Policy 4 (2019), 117-137.

3 The Internet Engineering Task Force, see below II.1.

4 Internet Corporation for Assigned Names and Numbers, ICAAN, see II.2. 
making differ significantly depending on the goals pursued: In the political sphere, the struggle for the right implementation of morals and values is in the foreground, ${ }^{5}$ while actors with a technical orientation collaborate in their focus on improving the infrastructure's efficiency and on practical questions of a coherent administration. In doing so, they all follow their own distinctive agendas. However, these decisions with their different aims and directions are in principle accepted by those affected by them - the users of cyberspace. In other words: Globally binding decisions made by state and non-state actors are de facto accepted, although there is no institutionalisation in sight: neither exist comprehensive treaties under international law nor a superordinate organisation dealing with the regulation of cyberspace. Therefore, legal theory is faced with a dilemma: Are these decisions legitimised? And if so, how?

Network theory can help to bring light into the darkness. It attempts to adapt legal theory to the development of an increasingly networked society by turning away from the classical understanding of (international) law theory, according to which it is primarily the formation of political will within states that has a legitimising effect on regulatory activity. Instead, it states that non-state actors, too, follow their own normative order and derive the legitimacy for their decisions from their own specific sources. In this way, network theory is able to link the seeming disorder of global regulatory efforts in general, and those in Cyberspace in particular, back to legal theory.

The present contribution looks at the activities of different non-state actors of cyberspace governance through the lens of network theory and examines if and how their decisions are legitimised. To this end, the first block (II.) analyses three particularly relevant actors involved in the governance of Cyberspace. Their mandates, structures, and the processes preceding their decisions are described in detail. The second part (III.) then uses network theory to examine if and how the entities' structures and processes affect the decisions' quality and legitimacy. To this end, network theory is first introduced (III.1.) and then carefully placed in relation to the previously analysed actors (III.2.). In this way, on the one hand, the statements of network theory are illustrated, and on the other hand, the legitimation paths of non-state actors' decisions in Cyberspace become comprehensible. The last part (IV.) summarises the findings of the study.

5 See only Alex Grigsby, 'The End of Cyber Norms', Global Politics and Strategy 59 (2017), 109-122. 


\section{Regulation of Cyberspace}

The selected institutions deal with the regulation of essential components of cyberspace. At the same time, their emergence follows chronologically the evolution of cyberspace development: Starting with the Internet Engineering Task Force (IETF), originator of Cyberspace' purely technical regime, followed by the Internet Corporation for Assigned Names and Numbers (ICANN) at the interface between the Internet's technical infrastructure and its increasing use by the general public and, last, the Internet Governance Forum (IGF), which provides a broad platform for exchange on technical as well as political issues of Cyberspace.

\section{IETF}

The IETF develops standards and protocols that ensure that any software can be used smoothly on any hardware, thus guaranteeing the Internet's interoperability. ${ }^{6}$ As the first and to date the most important standardisation organisation on the Internet, it is the crucial entity for the technical development of the Internet and the constant improvement of its functioning. ${ }^{7}$ The IETF is not of state origin: instead, it is a large and open community of network architects, Internet operators, users and scientists, all distinguished by technical excellence, working in an anarchic organisational structure. ${ }^{8}$ The standards and protocols developed by the IETF have de facto validity on a global scale through their acceptance by developers of both software and hardware.

\section{a) IETF's Structure and Working Procedure}

In terms of work processes, the IETF places particular emphasis on ensuring that the standards and protocols it develops are the result of consensus among its members rather than of democratic processes. ${ }^{9}$ The nature of this consensus is further defined in the most important rule that IETF has given itself: 'IETF consensus does not require that all participants agree although

6 Matthias C. Kettemann, The Normative Order of the Internet (Oxford: Oxford Scholarship Online 2020), 31-32.

7 About the IETF <https://www.ietf.org >.

8 See the IETF Mission Statement, RFC 3935, <https://tools.ietf.org >.

9 See the IETF's motto: 'We reject: kings, presidents, and voting. We believe in: rough consensus and running code.', IETF, RFC 7282, <https://tools.ietf.org>. 
this is, of course, preferred. In general, the dominant view of the working group shall prevail. (However, it must be noted that "dominance" is not to be determined on the basis of volume or persistence, but rather a more general sense of agreement.) Consensus can be determined by balloting, humming, or any other means on which the Working Group agrees (by rough consensus, of course)'. ${ }^{10}$ With regard to the structure of the IETF, the most striking characteristic is its openness to all persons interested. Standards and protocols are set in an open and transparent process in which all members can participate. ${ }^{11}$

The IETF splits its activities into thematic Areas, each of which consists of several Working Groups related to the focus of that Area; each Area is headed by an Area Director (AD), who is nominated for a two-year term by the Nominating Committee (NomCom), ${ }^{12}$ which chairs the IETF. ${ }^{13}$ Together with the Chair of the IETF, the ADs form the Internet Engineering Steering Group (IESG). ${ }^{14}$

The IETF's decisions are found in a dialogical, recursive process. When creating standards, the working groups publish their results as Requests for Comments (RFC). By doing so, the drafts enter into the approval process. ${ }^{15}$ As soon as the IESG approves an RFC, the standard becomes a Proposed Standard. It remains in this status for a period of six months during which it is discussed by all of the IETF-community. In case it is promoted to a Draft Standard, it enters into an implementation and test phase after which it can finally become an Internet Standard.

\section{b) IETF's Networked Standard Setting}

Since its foundation, the IETF follows the dogma of effectiveness and functionality. It aims at technical excellence, at being always up-to-date, and it realises a high degree of transparency by documenting every single development step of any protocol or standard. The open structure of the IETF and the fact that anyone interested can participate in the development of standards and protocols has the effect that all knowledge available among

10 IETF, RFC 7282, <https://tools.ietf.org >.

11 IETF, RFC $3935<$ https://tools.ietf.org>.

12 The NomCom is composed of a random selection of IETF volunteers, <https://www. ietf.org>.

13 IETF, RFC 8318, <https://tools.ietf.org>.

14 The IESG is responsible for the overall operation of the IETF; IETF, RFC 5742, $<$ https://tools.ietf.org $>$.

15 A description of the several steps can be found in RFC 2026, <https://tools.ietf.org >. 
individual actors is collected and made accessible via the RFCs, which circulate permanently among all members. The subsequent test phases assure that only those proposals that best solve the respective problem prevail. Therefore, the IETF's openness and its recursive processes assure that the maximum knowledge can be first collected and then channelled to be summarised in a decision.

\section{ICANN}

ICANN is a not-for-profit corporation, responsible for coordinating, administrating, and allocating the management of unique names and addresses on the Internet, known as domain names (e. g.: www.example.com). It also coordinates the operation and development of the root server system ${ }^{16}$ and organises the development of policies on Domain Name System (DNS) ${ }^{17}$ management issues. ${ }^{18}$ Thus, the technical management of a global key resource of the Internet lays in the hands of a non-governmental, decentralised entity that is neither a product of an international treaty nor an international organisation. ${ }^{19}$ Instead, representatives of various sectors - civil society, business, and governments - cooperate to produce decisions, which have an immediate effect on Cyberspace, and are accepted by the entire Internet community.

\section{a) ICANN's Evolution}

The DNS was developed by scientist and Internet pioneer Jon Postel who managed it with the Internet Assigned Numbers Authority (IANA) under the responsibility of the Defense Advanced Research Projects Agency (DARPA), an agency of the United States Department of Defence. ${ }^{20}$ With the massive increase in Internet use also beyond the research community in the 1990 s, and simultaneously growing commercial interests in the use of rele-

16 Thirteen root servers exist worldwide: ICANN Office of the Chief Technology Officer, Brief Overview of the Root Server System, 6 May 2020, 4.

17 The DNS translates the names of websites into binary addresses that the computer can read, and back again, e. g.: www.example.com = IPv4-Adresse: 93.184.216.34.

18 See Art. 1. 1 (a) (i) ICANN Bylaws. The Bylaws have undergone several updates. The rules quoted here are dated 28 November 2019, <https://www.icann.org>.

19 Kettemann (n. 6), 106.

20 Memorandum of Understanding on the Generic Top Level Domain Space of the Internet Domain Name System, (gTLD-MoU), <https://web.archive.org >. 
vant domain names, a more comprehensive management system became necessary. In 1998, the US-Government proposed the privatisation of DNS management in order to open up the Internet to a wider international scope and to strengthen it as a medium for communication and competition. ${ }^{21}$ The same year, ICANN was handed over to the international community, 22 and established as a private non-profit entity under the Law of California - 'a non-governmental organisation with significant responsibilities for administering what is becoming a global resource'. ${ }^{23}$ Since then, ICANN operates the IANA functions ${ }^{24}$ as the crucial entity at the interface between the technical network of Cyberspace and its use by the general public.

\section{b) ICANN's Structure and Working Procedure}

The rules and procedures of ICANN are set out in the Articles of Incorporation ${ }^{25}$ and the Bylaws. ${ }^{26}$ ICANN organises 'the development and implementation of policies [...] through a bottom-up consensus-based multistakeholder process'. ${ }^{27}$ Following this mandate, ICANN's structure is kept as open as possible to give those actors interested the possibility to participate. It is guided by IETF methods: when seeking decisions, general consensus should be realised wherever possible. ${ }^{28}$ Therefore, ICANN's operations are characterised by decentralised governance in which stakeholders from different sectors - individuals, industry, organisations with non-commercial interests, and governments - interact on an equal footing. ${ }^{29}$

\section{(i) Stakeholder Structure}

ICANN is headed by a Board of Directors composed of 21 members, representing three Supporting Organisations (sub-groups focusing on specific sections of ICANN's responsibilities), independent representatives of the general public interest, and finally the President and Chief Executive

21 National Telecommunications and Information Administration, Statement of Policy on the Management of Internet Names and Addresses, 5 June 1998.

22 Letter from Lawrence Strickling, NTIA, to Steve Crocker, regarding the Affirmation of Commitments, 6 January 2017, <https://www.icann.org>.

23 Jon Postel, Letter to William Daley, Secretary of Commerce, 2 October 1998, <https:// www.ntia.doc.gov>.

24 IANA, Introduction, <https://www.iana.org $>$.

$25<$ www.icann.org>.

$26<$ www.icann.org>.

27 Art. 1. 1 ICANN Bylaws.

28 ICANN Participation Booklet, <http://archive.icann.org>, 8.

29 ICANN, <www.icann.org>. 
Officer (CEO), appointed by the rest of the Board. In addition, ICANN can rely on several Advisory Committees, which make recommendations to the Board on matters that are within their respective areas of responsibility. ${ }^{30}$ The general public is involved especially via the Generic Names Supporting Organization (GNSO), which plays an important role among the supporting organisations. ${ }^{31}$ It is the responsibility of the GNSO council ${ }^{32}$ to develop and recommend to the ICANN board substantive policies regarding the generic Top Level Domains (gTLD) ${ }^{33}$ based on the input from four stakeholder groups, ${ }^{34}$ which reflect the great diversity of groups and individuals that make up the ICANN community, and from the 'constituencies'35 which each represent groups of Internet users sharing specific interests.

\section{(ii) Individual Internet Users}

To give individual Internet users a channel to advise on ICANN activities 'insofar as they relate to the interests of individual Internet users', ${ }^{36}$ the AtLarge Advisory Committee (ALAC) was created in 2002 to be the 'primary organisational home within ICANN for individual Internet users'. ${ }^{37}$ Again, a bottom-up mechanism ensures that all voices of individuals find their way up to the ALAC: any group in which individual users come together to share and discuss their views on ICANN issues can be registered as an At-Large Structure (ALS). ${ }^{38}$ These ALSes can take part in discussions hosted by the Regional At-Large Organizations (RALOs), ${ }^{39}$ which nominate two members of the ALAC each.

30 Art. 12 ICANN Bylaws.

31 The two other Supporting Organisations are the Address Supporting Organization (ASO), working on issues regarding the IP address allocation, and the country code Name Supporting Organization (ccNSO), developing country code policies.

32 On the structure of GNSO, see <https://gnso.icann.org>.

33 Cross-border domains such as .com.

34 The Commercial Stakeholder Group, Non-Commercial Stakeholder Group, Registrars selling domains - Stakeholder Group and Registries - maintaining TLDs - Stakeholder Group, $<$ https://gnso.icann.org>.

35 Technical term for internet users who group themselves according to certain topics or interests (within the Commercial Stakeholder Group, for example: the constituency of Commercial Business Users, Internet Service Providers or Intellectual Property).

36 Art. 12. 2. (d) (i) ICANN Bylaws.

37 Art. 12. 2. (d) (i) ICANN Bylaws.

$38<$ https://atlarge.icann.org>; e.g.: Computer User Organization, Internet civil society groups, consumer advocacy groups etc.

39 African (AFRALO), Asian, Australian and Pacific Islands (APRALO), European (EURALO), Latin American and Caribbean Islands (LACRALO) and North American (NARALO), see <https://atlarge.icann.org/>. 
(iii) Governments

National Governments are represented in the Governments Advisory Committee (GAC), ${ }^{40}$ which advises ICANN on 'activities as they relate to concerns of governments'. ${ }^{41}$ With regard to governments, the core values state that, although ICANN remains grounded in the private sector, it recognises the governments' and public authorities' responsibility for public policy. ${ }^{42}$ ICANN therefore commits to 'duly taking into account the public policy advice of governments and public authorities'. ${ }^{43}$ While the GAC has no direct control over ICANN, the Board must take particular account of the advice of the GAC and, for example, give specific reasons for any action that deviates from the GAC's vote or find mutually acceptable solutions in a special procedure. ${ }^{44}$ In addition, Article 12.2 (a) (xi) of ICANN's Bylaws gives the GAC a genuine veto right.

\section{c) Touchstone: The $. x x x-$ Case $^{45}$}

The fact that the possibilities of governments to influence ICANN are nevertheless precisely defined and limited became clear with the .xxx-case, when governments attempted to disrupt the balanced stakeholder relationship within ICANN. Following the GNSO's recommendation to introduce a limited number of new gTLDs, the ICANN Board launched the bidding process for the allocation of new gTLDs. The company ICM Registry responded by bidding for a gTLD named . $x x x$, which was specifically intended for 'adult-only' content. Already in 2000, ICANN had stated in response to moral concerns expressed by the GAC to recommend against the gTLD's selection 'because of the controversy surrounding [...] .xxx'.46 After ICANN agreed in principle to ICM Registry's application in the following procedure in 2005, and started contract negotiations, ${ }^{47}$ the process was initially suspended in $2006^{48}$ following pressure from certain

40 Art. 12.2 (a) ICANN Bylaws.

41 Art. 12.2 (a) (i) ICANN Bylaws.

42 Art. 1.2 (b) (vi) ICANN Bylaws.

43 Art. 1.2 (b) (vi) ICANN Bylaws.

44 Art. 12. 2 (a) (x) ICANN Bylaws.

45 See the in-depth analysis by The Berkman Center for Internet \& Society at Harvard University, Accountability and Transparency at ICANN - An Independent Review, 20 October 2010, Appendix D: The .xxx Domain Case and ICANN Decision-Making Processes.

46 ICANN, Report on TLD Applications of the August 15 Criteria to Each Category or Group, 9 November 2000, <https://archive.icann.org>.

47 ICANN, A Special Meeting of the Board, 1 June 2005, <https://www.icann.org >.

48 The Berkman Center (n. 45), 23. 
governments. ${ }^{49}$ However, after talks resumed in 2007, ICM's application was ultimately rejected on the grounds that it did not meet formal criteria. ${ }^{50}$ It was only in 2010 after several proceedings, that an Independent Review Panel (IRP), one of three mechanisms purposed for the review of ICANN board activities and decisions, ${ }^{51}$ decided that ICANN had made a legal error by listening to moral arguments, since it was only called upon to decide technical issues. ${ }^{52}$ The IRP also criticised the particular influence of the US, which wanted to impose its own ideas on morality (pornography respectively) in the online environment. As a result, the panel recommended ICANN to stay within its mandate and to act neutrally and 'consistently with relevant principles of international law',53 to which ICANN has committed itself in Art. 4 of the Articles of Incorporation.

\section{d) Hybrid Regulation of a Global Resource}

Similar to the IETF, ICANN's open and accessible structure ensures that all interested stakeholders can voice their interests within the DNS governance process. The rule is that the interests of all stakeholders are considered equally. This means that all interests are first collected and taken into account as far as necessary. However, because DNS governance is more complex in that it is not only about technical but also non-technical issues, ICANN's structure is split into many subgroups and therefore more complex than the IETF's structure. Although individual stakeholders, such as the governments, are formally given special recognition, it is nevertheless ensured that they do not negatively influence ICANN's core tasks. However, the .xxx-case showed that it was necessary to activate an independent institution to guard the organisation's rules and the fulfilment of its mandate. ${ }^{54}$

49 The USA and the US Department of Commerce were the main advocates, ICDR Case No. 50117 T 00224 08, Declaration of the Independent Review Panel, 19 February 2010, 17-19.

50 ICANN, Meeting of the ICANN Board, Lisbon, 28 March 2007, <https://www. icann.org>.

51 Art. 4. 2. ICANN Bylaws; an IRP is an arbitration tribunal. It is created any time there is an allegation against the Board and the appellant petitions for an independent review.

52 International Centre for Dispute Resolution, ICM Registry, LLC v. ICANN, ICDR Case No. 50117 T 00224 08, Independent Review Panel Declaration (2010).

53 ICM Registry, LLC v. ICANN, No. 140, 152.

54 The Uniform Domain Name Dispute Resolution Policy (UDRP) is another popular example to illustrate the emergence of a regime within ICANN that is independent of national and international law. See David Lindsay, International Domain Name Law: ICANN and the UDRP (Oxford: Hart Publishing 2007), 95-96 and Jochen von Bernstorff, 'The Structural Limitations of Network Governance: ICANN as a Case in Point' in: Christian Joerges, IngerJohanne Sand and Gunther Teubner (eds), Transnational Governance and Constitutionalism (London: Hart Publishing 2004), 252-287 (270). 


\section{IGF}

The Internet Governance Forum is an open discussion platform on central legal, political, social, and technical issues of the Internet. The IGF's mission is to develop ideas about the future shape of cyberspace. It therefore has a very broad approach to Cyberspace governance. All interested parties, especially non-state actors, can participate in the IGF's activities. However, the IGF has no decision-making power and (to date) merely serves as an opportunity for a broad exchange of ideas on Cyberspace governance.

\section{a) Evolution of the IGF}

The IGF was established in 2003/05 in the context of the World Summit on the Information Society (WSIS). The WSIS was organised by the International Telecommunications Unit (ITU) in implementation of UN General Assembly Resolution 56/18355 and took place in two phases, in Geneva in 2003 and in Tunis in 2005. The reason for the IGF's creation was that Internet governance issues were increasingly being discussed at international level, but no agreement was reached on the concrete future shape of Internet governance within the WSIS or elsewhere. The only agreement that could be reached in the end was that not only governments and institutions close to them, but also other sectors should be involved not only in the implementation of rules for Cyberspace but also in their creation. Accordingly, the Tunis Agenda as the final document of the WSIS formulates the conviction of the international community: '[...] The international management of the Internet should be multilateral, transparent and democratic, with the full involvement of governments, the private sector, civil society and international organisations. ${ }^{56}$

\section{b) Structure and Processes, Criticism and Reform}

The Tunis Agenda did not define the organisation of the IGF in detail, it only contains basic guidelines for the structure of the processes within the IGF: The IGF should work multilaterally, democratically, and transparently, following the multi-stakeholder model, ${ }^{57}$ while complementary stakeholders

55 UNGA Res 56/183 of 31 January 2002, A/RES/56/183, para. 1.

56 WSIS, Tunis Agenda for the Information Society of 18 November 2005, WSIS-05/ TUNIS/DOC/6(Rev.1)-E (in the following short: The Tunis Agenda), para. 29.

57 The Tunis Agenda, para. 29. 
should be taken into account. ${ }^{58}$ Following his mandate, the UN SecretaryGeneral established an office in Geneva in 2006 to support the IGF. He also created the Multistakeholder Advisory Group (MAG) ${ }^{59}$ to advise him during the annual IGF meetings. Many different activities also take place between the meetings, such as platforms for discussions on policy issues related to the Internet or Dynamic Coalitions. ${ }^{60}$ In addition, there are annual regional IGFs, which have no decision-making powers and are open to all interested parties acting formally on an equal footing. ${ }^{61}$

The IGF was conceived purely as a platform for discussion, in particular to prevent it - endowed with any form of decision-making power - from becoming a battleground for national governments with their differing views on Cyberspace. ${ }^{62}$ Accordingly, the individual sessions should produce neither decisions nor resolutions or norms, ${ }^{63}$ but instead recommendations. It was hoped that neutral discussions, in which all different opinions would be heard, would lead to good compromises based on facts, practicability and efficiency rather than on ideological differences or national power politics. ${ }^{64}$ This meant a conscious shift away from purely political will building and decision making. In addition, the Internet community, too, found it difficult to give the IGF decision-making power, to define its mandate too broadly or to set stricter standards for its processes; The IGF thus provides for a comprehensive exchange of ideas on a regular basis, keeping issues on the agenda for a long term. ${ }^{65}$

In the past few years, reform efforts have taken place to increase the IGF's influence. The major and much criticised disadvantage can be found in the fact that resulting ideas are not transferred or implemented into practical negotiations. ${ }^{66}$ For this reason, the UN initiated a global consultation process on the future architecture of Internet governance as part of its strategy to increase the effectiveness of cooperation in the field of communications and the Internet. ${ }^{67}$ These consultations resulted in an Options Paper, which brings

58 The Tunis Agenda, para. 73.

$59<$ https://www.intgovforum.org>; The MAG has 55 members representing governments, the private sector and civil society, including representatives from the academic and technical sectors.

60 Jeremy Malcolm, Multi-Stakeholder Governance and the Internet Governance Forum (Perth: Terminus Press 2004), 379-380; See the list at <https://www.intgovforum.org>.

61 See $<$ https://www.intgovforum.org $>$.

62 Malcolm (n. 60), 466.

$63<\mathrm{http}: / /$ www.intgovforum.org $>$.

64 Malcolm (n. 60), 356.

65 Kettemann (n. 6), 114.

66 Daniel Voelsen, 'Das Internet Governance Forum auf dem Prüfstand', SWP-Aktuell 59 (November 2019), <https://www.swp-berlin.org/10.18449/2019A59/>.

67 The UN Secretary General's High-level Panel on Digital Cooperation (HLPDC), The Age of Digital Interdependence, June 2019, 30, <https://www.un.org>. 
together the views of various stakeholders - the private sector, governments, civil society, technology, and science. It concludes that the IGF with its existing structures should be retained as the central platform for discussion, but should be significantly strengthened and made more effective. ${ }^{68}$ By transforming it into an Internet Governance Forum Plus (IGF+), more access and better coordination of all stakeholders should be promoted through financial support and a central information point. Furthermore, the IGF+ results are to be recorded in more action-oriented recommendations or reports so that they can be incorporated into political decision-making processes (still without the IGF becoming a treaty-making forum). ${ }^{69}$ The socalled Digital Commons Architecture (DCA) ${ }^{70}$ and the Distributed CoGovernance Architecture (CoGov) were discussed as alternative models, ${ }^{71}$ and elements of both models will be adopted in the IGF+. ${ }^{72}$

\section{c) Towards Comprehensive Cyberspace Regulation?}

The IGF was founded with the aim of coming closer to a comprehensive cyberspace governance. The open structure and the conception as a pure discussion platform are supposed to contribute to the gathering of as many ideas and conceptions on Cyberspace governance as possible, and to the alignment of expectations via dialogue. The IGF is thus designed for consolidation, but without being able or wanting to bring about decisions. Interestingly, however, it is precisely this characteristic, that is likely to prevent individual actors such as governments from becoming too strong.

\section{Interim Conclusion}

When looking at IETF, ICANN and IGF, we see a multitude of different actors coming together in different entities, in order to govern

68 UN HLPDC, Recommendation 5A/B, Options for the Future of Global Digital Cooperation, 2.

69 UN HLPDC (n. 68), 8.

70 The DCA places special emphasis on the use of technology to achieve the Sustainable Development Goals. Based on the 'Global Commons' in environmental law, it would focus on questions of accountability and trustworthiness.

71 The latter is essentially based on the self-forming network approach of ICANN and IETF and was intended to consist of various networks: 'Digital Cooperation Networks' should temporarily link various working groups on specific topics horizontally with each other; 'Network Support Platforms' would support the Digital Cooperation Networks; a 'Network of Networks' would perform coordination functions.

72 UN HLPDC (n. 68), 4. 
certain areas of Cyberspace. Hardly any instructions from the outside or from above are received or implemented in the processes of IETF, ICANN, or IGF; rather, governance emerges in the course of discursive processes, and is consolidated in decisions. However, these collections of actors and processes seem to fulfil their respective governance tasks efficiently, since the results are accepted and implemented worldwide. Since all three institutions are non-governmental, their decisions are not tied back to states; also, there is no overarching set of norms to guide the actors. Ways of legitimisation linked to states is therefore excluded. However, this does not necessarily mean that all the regulatory activities described are illegitimate. Rather, it is precisely the possibilities of legitimisation beyond the state that must be sought.

\section{Networks as Regularity in Irregularity}

One theory that presents a concept of international order by putting a special focus on transnational constellations is network theory. In the following, this theory will be briefly presented. It will be both illustrated and tested on the basis of the observations made on Cyberspace governance. Ultimately, an attempt is made to answer the question of where the order of Cyberspace governance derives its legitimacy from.

\section{Network Perspective}

To comprehend network theory, it is helpful to start with the very simple picture of a network and its properties: If one visualises a network, one thinks of a construct consisting of individual nodes, of the connections running between the nodes and of how the tension between the nodes hinders them to leave their place, ensuring that they cannot be arranged hierarchically but stay in a stable and heterarchic relationship to each other. The type and number of nodes and connections define the network's size and character, but are not necessarily predetermined. This idea of the network, initially established as a metaphor, has increasingly been elaborated as a fixed concept in various disciplines. The reception of network theory in international law scholarship has essentially taken place via governance research, ${ }^{73}$ an academic discipline in natural proximity to international law scholarship.

73 Michael M. Atkinson and William D. Coleman, 'Policy Networks, Policy Communities and the Problems of Governance', Governance 5 (1992), 154-180. 
In order to be able to grasp the significance of network theory for international law, the entry point here, too, is chosen via the insights of international relations.

\section{a) Early Reception of Networks in International Relations}

Already at an early stage, network theory was taken up in the discipline of International Relations in order to explain an increasingly empirical recognisable 'global governance'. ${ }^{74}$ Transgovernmentalism ${ }^{75}$ in particular uses the concept of a network to explain political and international issues, since the Westphalian model, according to which states only interact at government level, was not sufficient to explain the phenomena of globalisation. Keohane and Nye, for example, pointed out that the governmental level of interaction only represents one single segment of state interaction. According to them, interstate interaction is much more comprehensive and also takes place beyond the government level. ${ }^{76}$ They also noted an increasingly slow response capacity of individual governments to global problems and coined in this context the term 'ineffectiveness challenge'. ${ }^{77}$ These considerations were further specified by Slaughter. Slaughter considers the state to be a collection of private and public institutions such as banks, courts, or governments, ${ }^{78}$ having equivalents in other states. Like nodes of a network, these institutions are capable of making contact and exchange information with their counterparts abroad 79 in order to jointly and coherently regulate matters under their responsibility. ${ }^{80}$ This process is driven by the communications revolution ${ }^{81}$ and results in an increasingly dense network of the international community: one of public authorities at different levels of state hierarchy on the one

74 James N. Rosenau, 'Governance, Order and Change in World Politics' in: James N. Rosenau and Ernst Otto Czempiel (eds), Governance without Government: Order and Change in World Politics (Cambridge: Cambridge University Press 1992), 1-29 (1-3).

75 See for example Anne-Marie Slaughter, 'Government Networks: The Heart of the Liberal Democratic Order' in: Gregory H. Fox and Brad R. Roth (eds), Democratic Governance and International Law (Cambridge: Cambridge University Press 2000), 199-235 (201).

76 Joseph S. Nye Jr. and Robert O. Keohane, 'Transnational Relations and World Politics: An Introduction', International Organization 25 (1971), 329-349.

77 Robert O. Keohane, 'Governance in a Partially Globalized World', Am. Polit. Sci. Rev. 95 (2001), 1-13.

78 Anne-Marie Slaughter, 'Global Government Networks, Global Information Agencies, and Disaggregated Democracy’, Mich. J. Int'l L. 24 (2003), 1041-1071.

79 von Bernstorff (n. 54), 261.

80 See comprehensively Anne-Marie Slaughter, A New World Order (Princeton and Oxford: Princeton University Press 2004), 261-271.

81 Slaughter (n. 75), 200. 
hand, ${ }^{82}$ and one of non-state actors on the other. ${ }^{83}$ Slaughter summarises her observations with the concept of the 'disaggregated state', ${ }^{84}$ in which the state does not dissolve, but where it also no longer exclusively follows a hierarchical order. As a result, very different, relatively formal networks with global reach exercise the governance of functionally different areas, such as bank regulation and environmental protection. ${ }^{85}$ Slaughter believes that these kinds of networks could take over the functions of a world government without needing to establish a hierarchy. ${ }^{86}$ She thus departs from a strict distinction between domestic and foreign policy and instead calls for the use of transnational network structures to cope with global challenges, since these can hardly be mastered by the states alone. ${ }^{87}$

\section{b) Reception of Networks in International Law Scholarship}

Novel governance phenomena in the form of horizontal, transnational cooperation were initially clearly perceived in environmental law and international financial law. the increasing importance of non-state actors on the one hand and tendencies deviating from state sovereignty in connection with globalisation on the other could not be ignored for a long time in international law studies. However, a normative framework to capture these observations has long been lacking. Especially the classification of rules produced by non-state entities, questions about their normative quality and legitimacy posed a challenge to classical theories of law, which were characterised by an understanding of norm hierarchy, and based on the premise that norms are firstly legitimised by a will organised in the nation states. Connected to the latter premise is the notion of states as the only legitimate actors in international relations, ${ }^{88}$ and a shift away from this idea meant a radical rethinking of a fundamental premise of international law theories. Aimed at filling the

82 Slaughter (n. 75), 201.

83 Jan Hauke Plaßmann, 'Selbstermächtigung exekutiver Akteure: Demokratische Defizite und konzeptionelle Herausforderungen zwischenstaatlicher Netzwerke' in: Jonathan Bauerschmidt, Bardo Fassbender, Michael Wolfgang Müller and Angelika Siehr (eds), Konstitutionalisierung in Zeiten globaler Krisen (Berlin: Nomos 2015), 71-104 (74).

84 Slaughter (n. 80), 12; Slaughter (n. 75), 201; resp. with a focus on state sovereignty: AnneMarie Slaughter, 'Disaggregated Sovereignty: Towards the Public Accountability of Global Government Networks', Government and Opposition 39 (2004), 159-190.

85 Slaughter (n. 80), 2-3, 52-55 Slaughter (n. 75), 200. 214-216.

86 Anne-Marie Slaughter, The Chessboard and the Web: Strategies of Connection in a Networked World (New Haven and London: Yale University Press 2017), 202-206.

87 Slaughter (n. 75), 203, 234-235; Plaßmann (n. 83), 74-76.

88 Karl-Heinz Ladeur, 'Ein Recht der Netzwerke für die Weltgesellschaft oder Konstitutionalisierung der Völkergemeinschaft?', AVR 49 (2011), 246-275 (254). 
normative gap, the idea of the network has gradually established itself as a concept of international law ${ }^{89}$ and provides an increasingly well-defined term for conglomerates of heterarchic relationships between different more or less autonomous levels of multi-level governance. Network theory understands the formal definition criteria of international law as too rigid to be able to capture the area that lies between national law and international law. It therefore attempts to adapt legal theory to the networked society by creating a new framework for those forms of international governance that exist alongside formal state or intergovernmental institutions, and 'regulatory mechanisms in a sphere of activity which function effectively even though they are not endowed with formal authority'. ${ }^{90}$ By considering the emergence of functionally differentiated systems and their ways of interaction, network theory intends to assign a conceptual place to these networks and the law they produce - a place networks de facto possess.

Ladeur addressed the questions that globalisation poses for law at an early stage. ${ }^{91} \mathrm{He}$ observed the transnational convergence of certain thematic areas (such as environmental or financial issues) on the one hand and transnational regulatory efforts within these areas across territorial borders on the other. Other theorists such as Castells,,${ }^{92}$ Vesting, ${ }^{93}$ Viellechner, ${ }^{94}$ and Teubner have followed in noting that non-state actors increasingly produce non-state norms of varying legal quality which, even if not of equal strength, in principle have a globally binding effect. By escaping increasingly from national control, they saw functionally differentiated systems becoming networked, while the core of norm making processes shifted from its former nation-state centres to an independent transnational periphery. ${ }^{95}$ They noted that law does not develop

89 Thomas Vesting, Staatstheorie (Munich: Beck 2018), 157-176; Rakhyun E. Kim, 'Is Global Governance Fragmented, Polycentric, or Complex? The State of the Art of the Network Approach', International Studies Review (2019), 1-29; Manuel Castells, The Information Society: Economy, Society and Culture, Vol. 1: The Rise of the Network Society (Oxford: Blackwell 1996).

90 Rosenau (n. 74), 5.

91 See Karl-Heinz Ladeur, Postmoderne Rechtstheorie: Selbstreferenz, Selbstorganisation, Prozeduralisierung (Berlin: Duncker und Humblot 1992).

92 Manuel Castells (n. 89); Manuel Castells, The Information Society: Economy, Society and Culture, Vol. 2: The Power of Identity (Oxford: Blackwell 1997); Manuel Castells, The Information Society: Economy, Society and Culture, Vol. 3: End of Millennium (Oxford: Blackwell 2000).

93 Thomas Vesting, Die Medien des Rechts: Computernetzwerke (Weilerswist: Velbrück Wissenschaft 2015); Thomas Vesting, Rechtstheorie (2nd ed., Munich: Beck, 2015).

94 Lars Viellechner, Transnationalisierung des Rechts (Weilerswist: Velbrück Wissenschaft 2013); Lars Viellechner, 'The Network of Networks: Karl-Heinz Ladeur's Theory of Law and Globalization', GLJ 9 (2009), 516-536.

95 Gralf-Peter Callies, 'Systemtheorie: Luhmann/Teubner' in: Sonja Buckel, Ralph Christensen and Andreas Fischer-Lescano (eds), Neue Theorien des Rechts (Stuttgart: Lucius \& Lucius 2009), 71-74. 
exclusively hierarchically, but is increasingly produced by non-state actors who coexist heterarchically ${ }^{96}$ and replace the state as the sole author of law. ${ }^{97}$ These processes can be recognised in principle at 'all levels of public order, from the nation states to the global order'. ${ }^{98}$

\section{Cyberspace Governance Through the Lens of Network Perspective}

In the following, network theory is explained in the context of the IETF, ICANN, and IGF. The ideas of network theory are introduced and explained with reference to the three institutions. A focus is placed on the network characteristics, and how they affect the quality of the entities' regulatory activities and decisions. In this way, firstly, the claims of network theory are illustrated and made comprehensible. Secondly, however, the legitimation paths within the three institutions also become apparent.

\section{a) IETF, ICANN and IGF as Non-State Networks}

It has become very clear, that IETF, ICANN, and IGF perform tasks of the global Cyberspace Governance by developing coherent solutions across state borders, while existing and acting independent of nation States. If we think of the individual institutions as networks, in this picture the individual actors take the places of network nodes that are in permanent exchange with each other, which builds a connection between the Network nodes. There is no hierarchy between the network nodes; if any functions are assigned to individual members of the network, they are of coordinative nature.

\section{b) The Legitimacy of Networks and Their Decisions}

From the de facto accepted regulatory activity of non-state actors, network theory deduces that there is obviously no need for transcendental reasons

96 Angelo Jr Golia and Gunter Teubner, 'Networked Statehood: An Institutionalized SelfContradiction in the Process of Globalization?', MPIL Research Paper No. 2020-40, <https:// papers.ssrn.com/sol3/papers.cfm?abstract_id=3725646>, 5 .

97 Kettemann (n. 6), 189.

98 Karl-Heinz Ladeur, 'Globalization and the Conversion of Democracy to Polycentric Networks: Can Democracy Survive the End of the Nation State?', EUI Working Paper LAW 4 (2003), 23. 
inherent to a state to legitimise regulatory actions and decisions. ${ }^{99}$ While society is developing into a 'knowledge society', 100 the channelling, collection, and exploitation of knowledge is replacing morality and value concepts as sources of legitimacy. ${ }^{101}$ According to network theory, the interaction of various participants (visualised as network nodes), ${ }^{102}$ which all follow their own mandates differing in terms of content and function, results in an exchange of actor-specific knowledge by means of communication (visualised as connections between nodes), that can be collected in a common knowledge pool which then becomes the legitimating basis for actions. ${ }^{103}$ The fact that this pool of knowledge serves as a legitimising basis becomes particularly evident in the case of IETF and ICANN, whose decisions derive their normative force obviously not from the same grounds of legitimacy that underlie state decisions. With their focus on cyber specific regulatory activities, they primarily feed on technical knowledge and practical considerations. In case of the IETF, no need for transcendent grounds of legitimacy exists because of the decisions purely technical nature. It gets more interesting (and more obvious) with ICANN, where other than practical considerations, such as those of a moral nature, do not influence the work of ICANN (as could be seen very well in the . $x x x$-case). ${ }^{104}$ In the case of the IGF, the matter is more difficult because following the IGF's broad mandate, a large number of different interests convene. But here, too, the intention is to achieve governance precisely by turning away from states' and their grounds' influence.

\section{c) Feeding and Exploiting of the Knowledge Pool}

The next question is how exactly this knowledge pool is used. How is it fed and how does the knowledge in the network converge into decisions? Both is achieved through the network structure as well as through the processes inherent to networks.

99 Angelo Jr Golia and Gunther Teubner, 'Societal Constitutionalism (Theory of)', MPIL Research Paper No. 2021-08, <https://papers.ssrn.com/sol3/papers.cfm?abstract_id $=38040$ $941>, 1$.

100 Viellechner, Network (n. 94), 520.

101 Viellechner, Network (n. 94), 520.

102 Golia and Teubner (n. 96), 5.

103 Ladeur (n. 98), 17-20.

104 Which, by the way, does not mean that states cannot make political decisions within their own territory; they remain free, for example, to block certain domains altogether or to ban specific content. 
The network structure, in which the participants stand next to each other in a heterarchically, allows the knowledge pool to be filled with as many information as possible. By allowing all interested parties to become part of the network, their existing knowledge can be fed into the network. Since the link between the actors of a network is, firstly, based on cooperation ${ }^{105}$ and, secondly, relatively permanent, without being corporatised and too fixed, ${ }^{106}$ any actor can join the network without major difficulties and contribute with its specific knowledge to the common pool, the integration of as many participants as possible minimises the possibility that specific knowledge is overlooked.

How knowledge is collected within networks can be illustrated well by looking at the structure and functioning of IETF, ICANN, and IGF. The accumulation of as much information as possible provides the basis from which decisions are made. For the IETF it applies that there is no formal membership of the IETF; instead, any interested party can participate in the development of standards without representing specific bodies, to make sure that anyone's knowledge may find its way into the processes. ${ }^{107}$ The same is true for ICANN and IGF, where all stakeholders stand side by side in a strictly non-hierarchical way and where everyone who wishes can participate in both ICANN's and the IGF's tasks.

In a next step, the knowledge in the network is channelled to converge into decisions. That all knowledge available among the individual actors becomes accessible and finds its way into the decision-making, is ensured by the recursive, communicative processes between the network nodes. ${ }^{108}$ Within IETF, all members are granted the possibility to contribute to problem solving; everyone's suggestions are heard and considered until the best suitable standard or protocol prevails. The same applies to ICANN: All decisions are developed jointly by all participants in a discursive process. ICANN even established governing bodies to ensure that structure and processes are adhered to by all. IGF's processes, too, ensure that as much knowledge of different actors as possible is considered, even if the IGF does not (yet) produce binding decisions or norms. So far, it can be rather understood as one institutionalised discursive process on Cyberspace

105 Viellechner (n. 94), 520; Karl-Heinz Ladeur, Das Umweltrecht der Wissensgesellschaft (Berlin: Duncker und Humblot 1995), 22-45.

106 Gunther Teubner, 'Die vielköpfige Hydra: Netzwerke als kollektive Akteure höherer Ordnung' in: Patrick Kenis and Volker Schneider (eds), Organisation und Netzwerk: Institutionelle Stenerung in Wirtschaft und Politik (Frankfurt/Main: Campus-Verlag 1996), 189-216 (193).

107 IETF, RFC 2028, <https://www.rfc-editor.org>, 3.

108 Golia and Teubner (n. 96), 19. 
governance; 109 anyhow, the very fact that the IGF has no decision-making power is likely to encourage participants to engage rather unreservedly in the discourses which at least leads to filling the common knowledge pool. ${ }^{110}$

\section{d) Networks' Law and Legal Quality}

According to network theory, the work of the networks is not just a random regularity, but rather follows a certain order that is maintained by a specific law inherent to the networks which also defines the legal quality of the networks themselves. Teubner undertakes to specify both the law inherent to networks and, in a next step, the legal quality of networks themselves. As the special function of the law of networks, he recognises their capacity to bind uncertainties between the actors. ${ }^{111}$ By convening in the network, the actors are empowered to permanently observe themselves and others: Since the network nodes are permanently focused both on their own purpose and on the network's purpose (Teubner describes the nodes as double oriented), any decision, as soon as it is made, binds both the nodes themselves, but also the entire network (double attribution). ${ }^{112}$ By this way of permanent mutual observation and communication, they can both stabilise their expectations ${ }^{113}$ and strengthen the network as such. He further examines intensively the question of whether networked systems have their own particular constitution. In order to define a genuine constitutional concept for non-state regimes, he detaches the concept of the constitution from the nation state and considers which elements form its core, so that they can be absorbed and reapplied to new phenomena. He finds that it is not decisive whether or not a constitutional document exists, but if certain processes and key actors have been socially institutionalised. ${ }^{114}$ The decisive criterion for determining whether a constitution exists, is whether a network manages to keep its balance by resisting tendencies of monopolisation of individual actors. ${ }^{115}$ What is meant by this can again be clarified and further elaborated with reference to the IETF, ICANN, and IGF.

109 Kettemann (n. 6), 114.

110 Kettemann (n. 6), 115.

111 Gunther Teubner, 'Das Recht hybrider Netzwerke', ZHR 165 (2001), 550-575 (554557).

112 Teubner (n. 106), 199.

113 Teubner (n. 106), 199.

114 Gunther Teubner, 'Globale Zivilverfassungen: Alternativen zur staatszentrierten Verfassungstheorie’, HJIL 63 (2003), 1-28 (10).

115 Teubner (n. 114), 14-18. 
Assuming that a network's decision is best when all essential information is given equal attention, it is important not to give excessive weight to either individual pieces of information or single actors, because in this way, the process of knowledge channelling would be corrupted. A look at IETF and ICANN makes this clear: within the IETF, all actors pursue the uniform interest of finding best technical standards and protocols. Interests of a different than purely technical nature, such as moral-oriented ones, are irrelevant. Therefore, it is not conceivable that any other than technical interests influence the decision-making processes of the IETF. In contrast, when looking at ICANN and the .xxx-case, it becomes clear what is meant by monopolisation of individual actors (the push of states to impose their values onto Internet's infrastructure). Here, ICANN manages to counter these tendencies by establishing an independent dispute resolution body that interprets and applies the rules ICANN gives itself. In the case of the IGF, where value- or morality-related interests are raised alongside technical issues, monopolising tendencies are not only in principle conceivable. It was precisely to prevent such tendencies, namely the monopolising of state actors with their respective ideologies and interests, that it was not given decisionmaking power in the first place as a precaution. From a network perspective, IETF, ICANN, and IGF all have their own constitutionality.

\section{Order and Legitimacy Through Networks}

At the end of these considerations, it becomes clear that IETF, ICANN and IGF each realise network characteristics. On the one hand, these characteristics have the effect of creating knowledge pools of their own kind, which become a basis for decisions. These knowledge pools replace transcendent or otherwise superior reasons as the only sources of legitimacy. The network-specific structures and the processes cause that knowledge is first collected and made accessible, and then channelled in such a way that, firstly, irrelevant considerations with regard to the specific question are filtered out and, secondly, that knowledge can converge into decisions that are primarily knowledge-based.

\section{Concluding Remarks}

In the course of the study, it has become clear that essential institutions of cyberspace governance do not act randomly at all and that there is no cause 
for concern in view of the fact that essential regulatory decisions in cyberspace do not primarily originate from or are controlled by states. Rather, an order can be discerned in the activities that allows conclusions to be drawn about new stocks of legitimacy. Network theory is therefore able to provide information about these new stocks of legitimacy. It therefore seems in principle suitable for capturing new types of governance phenomena in legal theory.

Cyberspace seems to be a particularly good field for examining network theory. Indeed, it seems that what network theory has elaborated on a theoretical level becomes particularly clear in cyberspace, especially when one considers the beginnings of cyberspace and its development through associations of anarchic IT experts (such as the IETF). The comparison of IETF, ICANN, and IGF has also shown that all three entities follow the same pattern in their structure and processes. It is also noticeable that the complexity of their order grows with the complexity of their respective mandates. The more different interests have to be integrated into governance, the more difficult it is to maintain the balance between the participants. A particular difficulty seems to be the involvement of political or ideological stakeholders: ICANN has succeeded in countering monopolising tendencies of states by installing an external panel; if, on the other hand, one wanted to endow the IGF with more decision-making power, one would have to consider whether and which mechanisms could be installed to prevent monopolisation there, too, so that the IGF can produce efficient results.

Nevertheless, it should be borne in mind that this contribution only considered three individual institutions of cyberspace governance. It did not address how the institutions interact with each other, nor did it describe and analyse other entities. Therefore, it is by no means possible to deduce general statements about the governance of cyberspace. However, perhaps this contribution can at least serve as a proposal for further exploration of network theory. This engagement need not be limited to the activities of international non-state actors. Rather, it also seems worthwhile to examine it in the context of regulatory activity in general - be it national, international, non-state or state, since it may bring essential further development of legal theories. 
